Apparat zur Bestimmung der Kohlensäure. Von

\title{
Greiner and Friedrichs.
}

Der in Fig. 6 abgebildete Apparat hat im Princip Aehnlichkeit mit früher angegebenen. Die im oberen Gefäss befindliche Säure dient

Fig. 6.

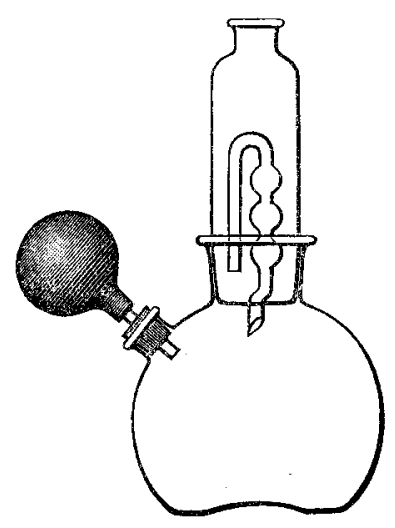
gleichzeitig zum Entwickeln und Trocknen der Kohlensäure. Letzt erwähntes Gefäss kann in den Hals des Kochfläschchens eingeschliffen oder mittelst Korks eingesetzt sein. Das Einführen der Säure in das untere Gefäss geschieht durch die Ansaugwirkung der Kautschukbirne, welche über das in dem Seitentubus befindliche Röhrchen geschoben ist. Durch schwächeres oder stärkeres Zusammendrüeken der Kautschukbirne hat man es in der Hand, mehr oder weniger Säure eintreten zu lassen.

Der Apparat ist leicht, wenig zerbrechlich und in Folge seiner einfachen Construction billig herzustellen.

Stützerbach i. Thür.

\section{Mittheilungen aus dem chemischen Laboratorium des Prof. Dr. R. Fresenius zu Wiesbaden.}

\author{
Ueber die Trennung des Baryts vom Kalk. I. \\ Von
}

\section{R. Fresenius.}

Anschliessend an meine kritische Bearbeitung der Methoden zur Trennung des Baryts vom Strontian lasse ich nunmehr auch eine solche der zur Trennung des Baryts vom Kalk im Gebrauche befindlichen oder in Vorschlag gekommenen Verfahrungsweisen folgen. $\mathrm{Zu}$ den Versuchen dienten, wenn andere Angaben nicht gemacht werden, Lösungen von 